\title{
Bottom-up Formation of Carbon-Based Structures with Multilevel Hierarchy from MOF-Guest Polyhedra
}

Tiesheng Wang, ${ }^{\dagger}+\odot$ Hyun-Kyung Kim, ${ }^{\dagger}{ }^{\circ}$ Yingjun Liu, ${ }^{\dagger}$ Weiwei $\mathrm{Li}^{\dagger}{ }^{\dagger}$ James T. Griffiths, ${ }^{\dagger}{ }^{\circ}$ Yue Wu, ${ }^{\dagger}$

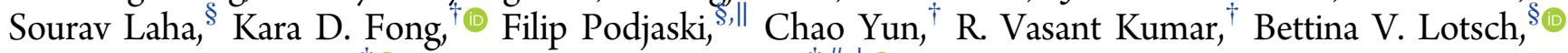
Anthony K. Cheetham, ${ }^{\dagger}$ and Stoyan K. Smoukov $\left.{ }^{*},, \#, \perp^{+(}\right)$

${ }^{\dagger}$ Department of Materials Science and Metallurgy, University of Cambridge, 27 Charles Babbage Road, Cambridge CB3 0FS, United Kingdom

${ }^{\ddagger}$ EPSRC Centre for Doctoral Training in Sensor Technologies and Applications, University of Cambridge, Philippa Fawcett Drive, Cambridge CB3 0AS, United Kingdom

${ }^{\S}$ Max Planck Institute for Solid State Research, Heisenbergstraße 1, 70569 Stuttgart, Germany

"École Polytechnique Fédérale de Lausanne, Station 12, 1015 Lausanne, Switzerland

${ }^{\#}$ School of Engineering and Materials Science, Queen Mary University of London, London E1 4NS, United Kingdom

${ }^{\perp}$ Department of Chemical and Pharmaceutical Engineering, Faculty of Chemistry and Pharmacy, Sofia University, 1 James Bourchier Avenue, Sofia 1164, Bulgaria

\section{Supporting Information}

ABSTRACT: Three-dimensional carbon-based structures have proven useful for tailoring material properties in structural mechanical and energy storage applications. One approach to obtain them has been by carbonization of selected metal-organic frameworks (MOFs) with catalytic metals, but this is not applicable to most common MOF structures. Here, we present a strategy to transform common MOFs, by guest inclusions and high-temperature MOF-guest interactions, into complex carbon-based, diatom-like, hierarchical structures (named for the morphological similarities with the naturally existing diatomaceous species). As an example, we introduce metal salt guests into HKUST-1-type MOFs to generate a family of carbon-based nano-diatoms with two to four levels of structural hierarchy. We report control of the morphology by simple changes in the chemistry of the MOF and guest, with implications for the formation mechanisms. We demonstrate that one of these structures has unique advantages as a fast-charging lithium-ion battery anode. The tunability of composition should enable further studies of reaction mechanisms and result in the growth of a myriad of unprecedented carbon-based structures from the enormous variety of currently available MOF-guest candidates.

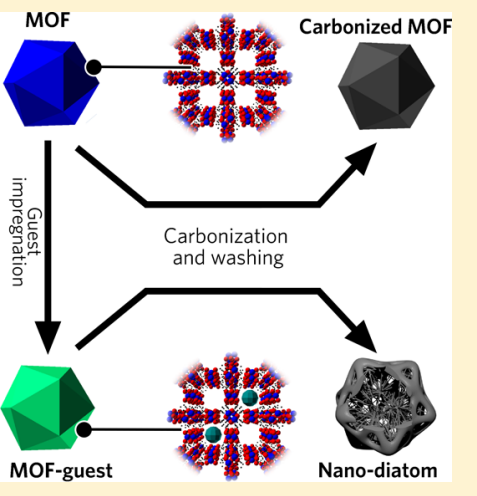

\section{INTRODUCTION}

Three-dimensional carbon-based structures with multilevel hierarchy ${ }^{1-7}$ from low-dimensional nanostructured building blocks (e.g., carbon dots, fullerenes, nanofibers/tubes, and graphene) can greatly exceed the properties of bulk carbon materials in numerous applications, such as lightweight but strong structures ${ }^{4}$ and energy storage. ${ }^{5-8}$ Multistep procedures and complex templates are commonly used to fabricate these materials, but few structures with multilevel hierarchy have been formed via facile bottom-up approaches. ${ }^{3,5}$ Recent work has explored carbonizing metal-organic frameworks $(\mathrm{MOFs})^{7-15}$ and in a few cases with $\mathrm{Ni}, \mathrm{Co}, \mathrm{Fe}$, and other catalytically active metals centers (as a part of the MOF's secondary building unit) has resulted in carbon-fiber assemblies. $^{16-23}$ Guest incorporation in the open porous MOFs can render the MOFs with tunable chemical composition and additional functionality. ${ }^{24-28}$ So far, MOFguest systems, such as Mo-based polyoxometalate@HKUST-
$1(\mathrm{Cu}){ }^{29}$ W-based metal-carbonyl@MAF-6(Zn), ${ }^{30}$ Ti-oxo clusters@HKUST-1 $(\mathrm{Cu}),{ }^{31}$ and dicyandiamide $/ \mathrm{FeCl}_{3} @ \mathrm{MIL}-$ $101-\mathrm{NH}_{2}(\mathrm{Al}){ }^{32}$ have been carbonized to produce advanced electrocatalysts or photocatalysts with desired compositions. However, neither a drastic morphology change nor carbonbased hierarchical structure formation was reported.

Here, we present an approach based on MOF-guest precursors and show a general strategy to transform common (noncatalytically active) MOFs into carbon-based structures with multiple levels of hierarchy via a simple thermochemical treatment (pyrolysis followed by washing). Since the method is developed based on guest impregnation rather than chemical functionalization (i.e., chemical bond formation), all the openporous MOFs that can take up the desired guests can be potentially used as the precursor. By changing the type of guest

Received: March 1, 2018

Published: April 23, 2018 
and host, we produce a family of carbon-based "nano-diatoms" with ordered hierarchical structures and investigate the combined effects of substituting the MOF or guest with control over the morphology of the resulting carbonaceous material. One of the nano-diatoms is demonstrated to be superior for fast-charging lithium-ion battery $(\mathrm{LiB})$ anodes ${ }^{33-35}$ with high storage capacity and stability.

Compared with direct MOF carbonization, which requires specialized MOFs (i.e., MOFs containing Ni, Co, and other catalytically active metal centers), carbonizing MOF-guest precursors is an alternative but much more versatile approach to achieve hierarchical carbon-based structures. Meanwhile, other inorganic elements/compounds introduced from both guests and MOF hosts can be incorporated into the pyrolyzed products (i.e., nano-diatoms). Further exploration of this hightemperature guest-induced phenomena on the broad range of available MOF-guest combinations ${ }^{36}$ will allow bottom-up fabrication of a new class of 3D structures with multilevel hierarchy for practical use in energy storage, energy conversion, and sensing.

\section{RESULTS AND DISCUSSION}

Pyrolyzing (at $800{ }^{\circ} \mathrm{C}$, under Ar) only a MOF precursor (Figure 1a) yields the polyhedral geometry of the original MOF

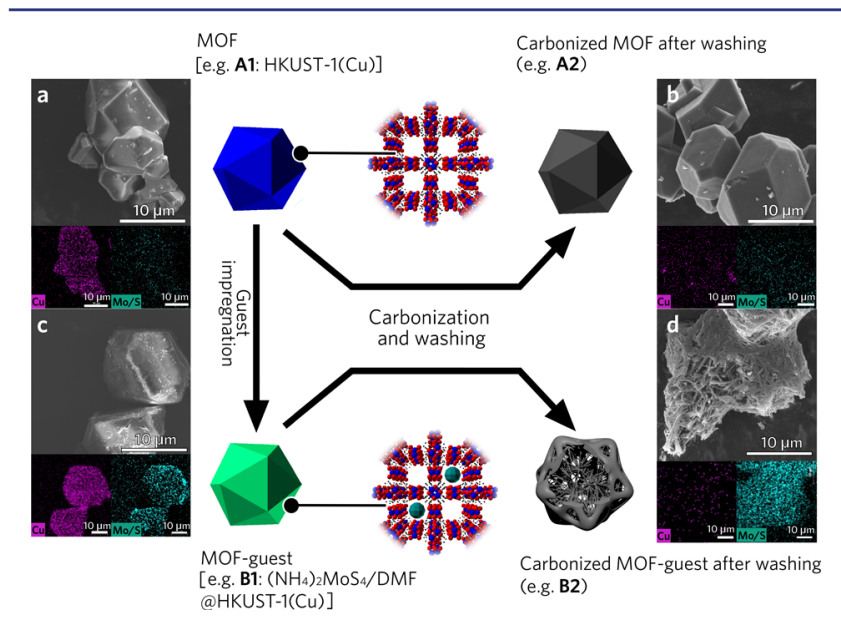

Figure 1. Microstructure and fabrication summary. (a) Secondary electron SEM (SE-SEM) image of HKUST-1 $(\mathrm{Cu})$ particles (A1); the MOF particles retain their polyhedral particle-like morphology but lose their crystallinity after pyrolysis (A2) at $800{ }^{\circ} \mathrm{C}$ under $\mathrm{Ar}$ followed by washing as observed in (b) and Figure S9. In contrast, a MOF-guest system, $\left(\mathrm{NH}_{4}\right)_{2} \mathrm{MoS}_{4} / \mathrm{DMF} @ \operatorname{HKUST-1}(\mathrm{Cu})$ [B1, pictured in (c)], turns into a highly distorted carbon-based nano-diatom containing fibers/webs (d) after the same treatment (B2). All the SE-SEM images are accompanied by the energy-dispersive X-ray spectroscopy (EDS) maps from SEM for $\mathrm{Cu}$ and Mo/S (Mo L $\alpha$ emission overlapping with $\mathrm{S} \mathrm{K} \alpha$ emission): A1 (containing $\mathrm{Cu}$ but not $\mathrm{Mo} / \mathrm{S}$ ) becomes $\mathbf{A 2}$ (without $\mathrm{Cu}$ or $\mathrm{Mo} / \mathrm{S}$ ) after carbonization and $\mathrm{Cu}$ removal step (i.e., washing); B1 (containing both $\mathrm{Cu}$ and $\mathrm{Mo} / \mathrm{S}$ ) turns into $\mathbf{B 2}$ (with $\mathrm{Mo} / \mathrm{S}$ but not $\mathrm{Cu})$ after the same treatment.

crystals with an amorphous carbon structure (Figure $1 \mathrm{~b}$ and Figure S9). However, pyrolyzing a MOF precursor with a metal-based guest under the same conditions (Figure 1c) still partly preserves the external polyhedral geometry but also produces fibers inside resembling those in diatoms. Subsequent washing dissolves some metal-based byproducts from the MOF host, resulting in mesopores. We study in detail the Cu-based MOF [HKUST-1 $(\mathrm{Cu}),{ }^{37,38}$ Al] impregnated with a Mo-based guest, ammonium tetrathiomolybdate, ${ }^{39}\left[\left(\mathrm{NH}_{4}\right)_{2} \mathrm{MoS}_{4}, \mathrm{ATM}\right]$, in dimethylformamide (DMF) solution to form our MOFguest system $\left[\left(\mathrm{NH}_{4}\right)_{2} \mathrm{MoS}_{4} / \mathrm{DMF} @ \operatorname{HKUST}-1(\mathrm{Cu}), \mathrm{B1}\right]$ (detailed in Supporting Information Sections 1.3.1 and 1.3.2, Figures S1-S5). The guest-free $\mathrm{MOF}$ (A1) has a high $\mathrm{N}_{2}$ adsorption volume $\left(\mathrm{N}_{2}\right.$ adsorption measurements in Figure S17a), while the MOF-guest (B1) has negligible $\mathrm{N}_{2}$ uptake volume, indicating that the pores in $\mathbf{B} \mathbf{1}$ are filled up. Here, the open nanoscale MOF porosity enables homogeneous hostguest mixing and inhibits segregation induced by reactions, resulting in a unique catalyst composition that eventually transforms the precursor into the structure of B2 (Figure 2) after pyrolysis and subsequent washing (detailed in Supporting Information Section 1.3.3, Figures S7 and S8).

Detailed morphological characterization reveals a hierarchical carbon-based nano-diatom, B2, with four levels of structure over a wide range of length scales. At the outermost level (i) the boundaries of the original MOF-guest particle are still visible (typically ca. $15 \mu \mathrm{m}$, shown in Figure 1d, Figure S13). These particles are composed of (ii) webs (typically $0.5-1 \mu \mathrm{m}$ in width, shown in Figure 2a-e and Figure S14b) at the outer surface and (iii) fibers inside the diatom (typically ca. $100 \mathrm{~nm}$ in diameter and ca. a few $\mu \mathrm{m}$ in length, shown in Figure $2 \mathrm{f}, \mathrm{g}$ and Figure S15). Additionally, both the webs and fibers have (iv) mesopores (typically ca. $20 \mathrm{~nm}$ in diameter, shown in the high-resolution DF-STEM images of Figure 2c,h, Figure S14b, and Figure S15) created by Cu-particle removal (details in Supporting Information Section 1.3.4), where metallic $\mathrm{Cu}$ particles are formed during the pyrolysis of the Cu-based MOF [supported by powder X-ray diffraction (PXRD) patterns in Figures S8 and S9]. The presence of mesopores in both A2 and B2 was further confirmed by pore diameter distributions obtained from $\mathrm{N}_{2}$ adsorption measurements (Figure S17d). While the webs and fibers mostly consist of $\mathrm{C}$, they have a small amount ( $<10$ wt \% each obtained by TGA in Figure S18) of Mo and $S$ dispersed in them, as shown in EDS mapping in Figure $2 \mathrm{e}$ and $\mathrm{j}$ and Mo $3 \mathrm{~d}$ and $\mathrm{S} 2 \mathrm{p}$ X-ray photoelectron spectroscopy (XPS) spectra in Figure $2 \mathrm{~m}$ and $\mathrm{n}$.

Comparing the products of $\mathbf{A 1}$ and $\mathbf{B 1}$ after identical carbonization treatments (Figure 1), only the host-guest precursor B1 yields a hierarchically structured nano-diatom (B2), whereas treatment of A1 gives rise to amorphous carbonized structures (A2) with the shape of the initial MOF crystals. We also prepared a control sample impregnated only with DMF [DMF@HKUST-1 $(\mathrm{Cu}), \mathrm{C1}]$. C1 behaves similarly to A1, yielding no significant morphological changes upon thermal treatment (Figure S12).

To reveal the elementary processes contributing to the structure formation of B2, we performed systematic characterizations at various temperatures in our thermal treatment profile (Figure S7) and stages of the reaction. The results are provided in the Supporting Information Section 4, where the deduced reactions are summarized in Figure S24. Briefly, as outlined by the evidence that follows, the guest decomposes to Mo-based species, which strongly interact with the pyrolyzing species to temperatures exceeding $600{ }^{\circ} \mathrm{C}$. The majority of the $\mathrm{Cu}$ formed from MOF decomposition and carbonization condenses on the outside of the carbon matrix, while a small portion of it, together with the Mo species, catalyzes the formation of fiber-like carbon-based structures from pyrolysis products of organic ligands.

Below ca. $300{ }^{\circ} \mathrm{C}$, we notice the DMF gasification/physical desorption and ATM decomposition [detected by ammonia 

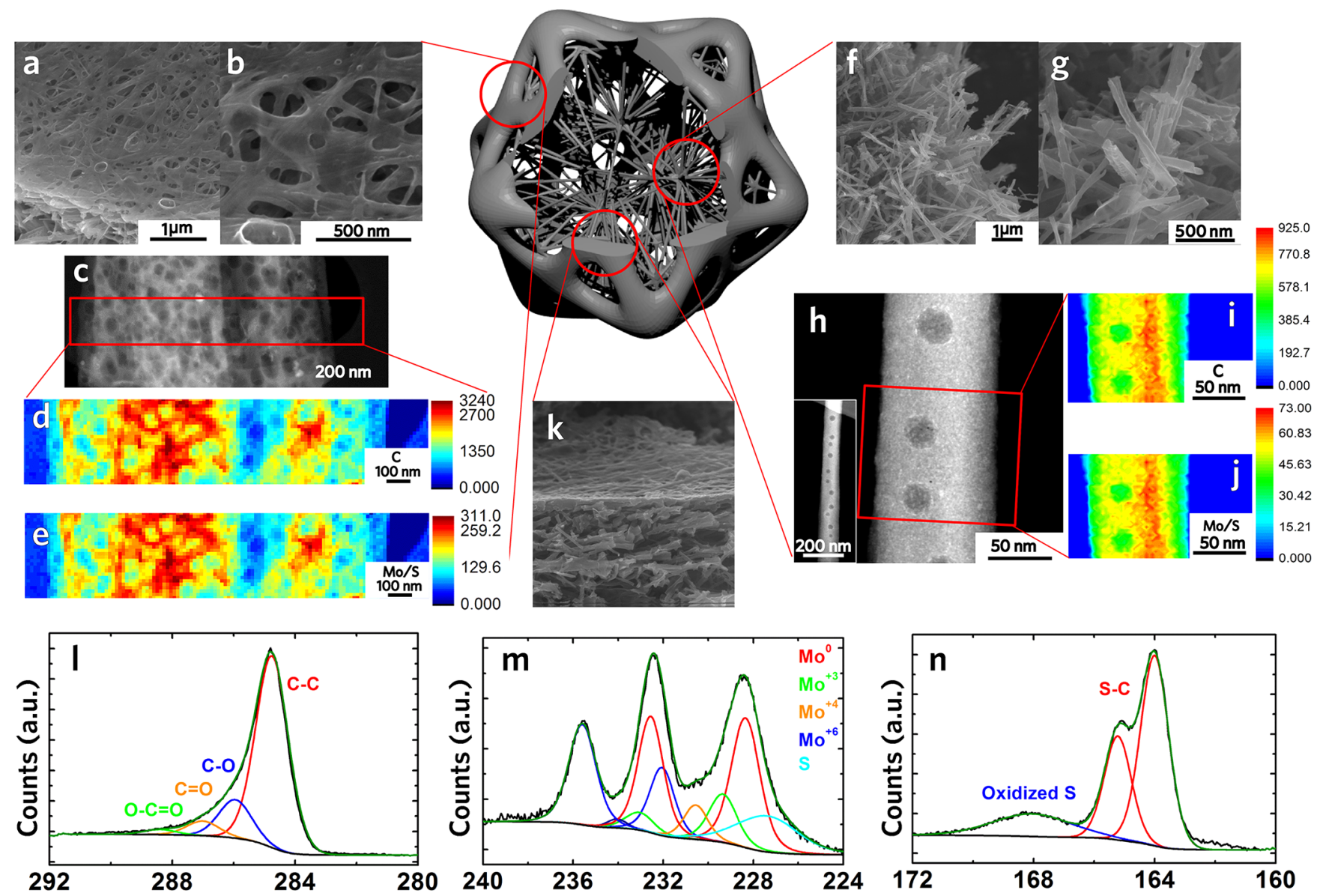

Figure 2. Characterization of B2. For the web-like surface, (a and b) SE-SEM images; (c) dark-field scanning transmission electron microscope (DFSTEM) images; and ( $\mathrm{d}$ and e) STEM EDS elemental maps of $\mathrm{C}$ and Mo/S. For fiber-like structure, (f and g) SE-SEM images; (h) DF-STEM images; and ( $\mathrm{i}$ and $\mathrm{j}$ ) EDS elemental maps of $\mathrm{C}$ and Mo/S. SE-SEM image (k) reveals the conjunction between the web-like surface and the fiber-like structure. EDS elemental maps reveal an abundance of carbon as well as homogeneous incorporation of Mo and/or S (the Mo L $\alpha$ peak overlaps with that of S K $\alpha$ ). XPS spectra are also shown: (l) C 1s; (m) Mo 3d + S 2s; and (n) S 2p. The XPS results also confirm the presence of C, Mo, and S. The $\mathrm{C} 1 \mathrm{~s}$ signal is strongly dominated by a $\mathrm{C}-\mathrm{C}$ peak at around $284.8 \mathrm{eV}$. The Mo $3 \mathrm{~d}$ peak at $228.7 \mathrm{eV}$ (for $\left.\mathrm{Mo}^{0}\right)^{40}$ suggests Mo-C bond formation. The $\mathrm{S} 2 \mathrm{p}$ doublets at ca. $164 \mathrm{eV}\left(\mathrm{S} 2 \mathrm{p}_{3 / 2}\right)$ and ca. $165 \mathrm{eV}\left(\mathrm{S} 2 \mathrm{p}_{1 / 2}\right)$ indicate the formation of S-C bonding. ${ }^{34}$ The presence of Mo and S supports the unique guest-MOF interactions during pyrolysis. $\mathrm{Mo}^{6+}$ and oxidized organic $\mathrm{S}$ are likely to be generated by interactions with entrapped $\mathrm{O}$ from the MOF host during carbonization and/or oxidation during the washing step with $\mathrm{FeCl}_{3}(\mathrm{aq})$ to remove $\mathrm{Cu}$.

formation ${ }^{41}$ by thermogravimetric analysis coupled with Fourier transform infrared spectroscopy (TGA-FTIR) in Figure S20]. In Mo 3d XPS spectra (Figure S21), corresponding peak shifts (from ca. 228 to ca. $232 \mathrm{eV}$ for Mo $3 \mathrm{~d}_{5 / 2}$ and from ca. $231 \mathrm{eV}$ to ca. $235 \mathrm{eV}$ for Mo $3 \mathrm{~d}_{3 / 2}$ ) are found during ATM decomposition, indicating significant change in Mo's valence. ${ }^{41,42}$ Also, slightly below $300{ }^{\circ} \mathrm{C}$, the MOF host loses its crystalline structure [confirmed by PXRD patterns in Figure S22]. Then, pyrolysis (i.e., a carbonization process) starts between ca. 300 and ca. $400{ }^{\circ} \mathrm{C}$, entailing decomposition of the organic ligands of the MOF (e.g., 1,3,5-benzenetricarboxylate) to carbon-based molecules through dissociation of carboxylate groups and gasification. This is discerned by $\mathrm{CO}_{2}$ production collected by TGA-FTIR (Figure S20) and the disappearance of $\mathrm{O}-\mathrm{C}=\mathrm{O}$ bonding in the $\mathrm{C} 1 \mathrm{~s}$ peak in the XPS spectra at ca. $288.8 \mathrm{eV}$ (Figure S21), as well as the production of metallic $\mathrm{Cu}$ particles (PXRD patterns in Figure S22). Meanwhile, evidence of strong interaction between Mo and the pyrolyzed MOF host extends well in the range of 300 to over $600{ }^{\circ} \mathrm{C}$; XPS Mo $3 \mathrm{~d}$ peaks stay at significantly higher binding energies (Mo $3 \mathrm{~d}_{5 / 2}$ at ca. $232 \mathrm{eV}$ and $3 \mathrm{~d}_{3 / 2}$ at ca. $235 \mathrm{eV}$ ), preventing significant formation of free $\mathrm{MoS}_{2}\left(3 \mathrm{~d}_{5 / 2}\right.$ at $229.1 \mathrm{eV}$ and $3 \mathrm{~d}_{3 / 2}$ at 232.3
$\mathrm{eV}$ ), which is one of the usual pathways for decomposing ATM in the similar temperature range under Ar. ${ }^{42}$ This is likely the reason that Mo compounds stay in the pyrolyzed matrix, as evidenced by EDX (Figure 2e and j) and Mo 3d XPS spectra (Figure $2 \mathrm{~m}$ and Figure S21).

Heating to $600{ }^{\circ} \mathrm{C}$ and higher, the $\mathbf{A 1} \rightarrow \mathbf{A 2}$ (Figure $1 \mathrm{~b}$ ) or $\mathbf{C 1} \rightarrow \mathbf{C 2}$ (Figure S12) transitions are predictable, which preserve the initial polyhedron shapes and are governed by noncatalytic pyrolytic processes ${ }^{43}$ (including decomposition, gasification, shrinkage, and bond re-formation of organic precursors). By contrast, starting at $600{ }^{\circ} \mathrm{C}$ the guestimpregnated precursor B1 starts to form fibrous carbon-based nanostructures. Dendrite-like surface features are present, as well as a macroporous interior network (SEM image, Figure S23). The fiber/web-like features become more developed at $800{ }^{\circ} \mathrm{C}$ (Figure S23). We hypothesize the unique hierarchical structure of our nano-diatom (B2) is produced through a hybrid reaction-diffusion process ${ }^{44}$ combining both pyrolysis and metal-based catalysis, as observed in other filamentous carbon formations (known for $\mathrm{Fe}-, \mathrm{Ni}-$, and Co-based catalysts ${ }^{44,45}$ ), where both $\mathrm{Cu}$ and Mo species could play key roles in the catalysis. These processes reconfigure the carbon in 
the original MOF material to create fiber and web-like carbonbased structures through reactions we later show depend strongly on the identities of the metals in the MOF and guest.

We verify the presence of both $\mathrm{Cu}$ particles (PXRD patterns in Figure S22) and Mo-C guest derivatives ${ }^{40}$ (found by Mo 3d XPS spectra in Figure $2 \mathrm{~m}$ and Figure S21). While $\mathrm{Cu}$ particles are formed in both carbonized A1 and B1 from $400{ }^{\circ} \mathrm{C}$ (Figure $\mathrm{S} 22$ ), metallic $\mathrm{Cu}$ by itself is typically ineffective for catalysis of carbon-based nanostructure growth ${ }^{46,47}$ even at $800{ }^{\circ} \mathrm{C}$, as shown for the A1 $\rightarrow$ A2 transition. Mo alone (present in the guest) is also unable to catalyze the formation of carbon-based nanostructures, as its strong interaction with carbon yields molybdenum carbides. ${ }^{29,48} \mathrm{Cu}$ combined with $\mathrm{Mo}$, however, can contribute synergistically to the growth of fiber-like carbon structures, as investigated previously by Holmes et al. ${ }^{47,49}$ Mocontaining species by themselves can crack the $\mathrm{C}-\mathrm{C}$ bond of organic compounds at high temperatures. ${ }^{50,51}$ In the presence of $\mathrm{Cu}$, however, Holmes' density functional theory (DFT) calculations predict that a $\mathrm{Cu}$ particle in proximity to a Mo can have sufficient binding energy to stabilize the formation of carbon-based structures such as nanotubes. In this way we hypothesize that carbon fragment remnants of the MOF cracked by the Mo-containing species re-form into carbon nanofibers (i.e., filamentous growth of carbon ${ }^{52,53}$ ) by the joint action of $\mathrm{Cu}$-based and Mo-based catalysts. The $\mathrm{Cu}$ particles within the pyrolyzed matrix act as growth locations for the fibers.

We are aware that the same metal compound in different environments can exhibit very different reactivity. The structural correlations and presence of the same metals in our system, however, yield the working hypothesis that catalytic interactions contributed from both our Cu-based MOF host and Mo-based guest system lead to the formation of fiber and web-like carbon-based building blocks of the nano-diatom. The $S 2 p$ XPS spectrum in Figure $2 n$ shows that as a side reaction $\mathrm{S}-\mathrm{C}$ may be formed as well.

Meanwhile, we notice that the nanostructured carbonaceous building blocks are confined by the boundaries of the original MOF-guest crystal B1 (Figure 2k and Figure S13). Metalcarbon interactions and the mobility of metal-based species may account for such confined growth. Mo prefers to stay in the carbonaceous matrix due to its strong affinity to C. ${ }^{47-49} \mathrm{~A}$ significant amount of $\mathrm{Cu}$, however, migrates out of the carbonized matrix due to weak $\mathrm{Cu}-\mathrm{C}$ interactions ${ }^{46}$ and condenses on the surface. Such condensed $\mathrm{Cu}$ particles are later removed in the washing process, which leaves a diatom surface densely populated with mesopores formed by their dissolution (Figure 2c), compared to fibers inside (Figure 2h) with spherical holes in the DF-STEM images indicating the $\mathrm{Cu}$ particle removal. This accumulation of $\mathrm{Cu}$ on the surface disrupts the $\mathrm{Cu} / \mathrm{Mo}$ ratio necessary for catalysis and inhibits outward growth of the fibers. ${ }^{47}$ Consequently, the fibers are confined in a cage (i.e., the web-like structure observed in Figure $2 \mathrm{a}-\mathrm{c}$ ) with dimensions based on the original MOF host. To verify these mechanistic hypotheses, we systematically investigated a series of MOF-guest combinations, where we replaced the reactive metals either with homologous metals or with oxide-forming rather than carbide-forming species that would inhibit the metal-catalyzed carbon-forming reaction (Figure 3).

For positive verification of the mechanism we first replaced Mo with W, a homologous group VI element predicted to have similar reactivity. ${ }^{48,49}$ Indeed, by placing ammonium tetrathio-
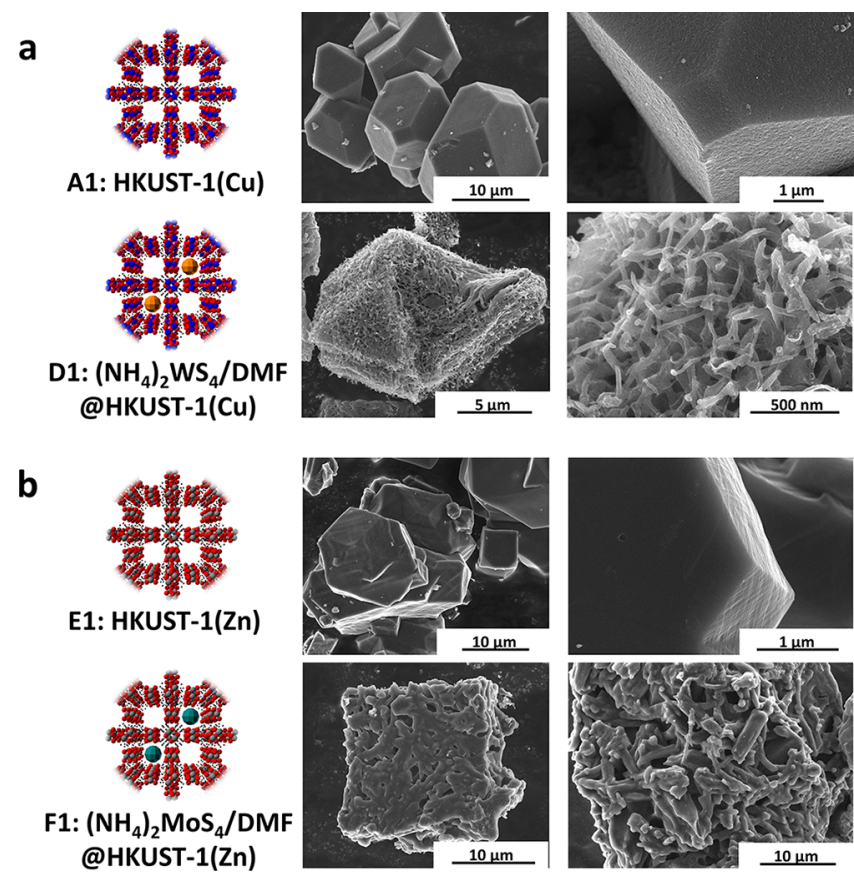

Figure 3. Summary of combined effects of substituting the MOF or guest on the morphology of nano-diatoms after carbonization. Schematic illustrations of precursors (left column) and SE-SEM images of products (two columns on the right-hand side) after the thermochemical treatment of (a) A1 (top) and D1 (bottom); and (b) E1 (top) and F1 (bottom).

tungstate $^{39}\left[\left(\mathrm{NH}_{4}\right)_{2} \mathrm{WS}_{4}\right.$ or ATT $]$ instead of our original guest ATM, we form MOF-guest $\left(\mathrm{NH}_{4}\right)_{2} \mathrm{WS}_{4} / \mathrm{DMF} @ H K U S T$ $1(\mathrm{Cu})$ (D1), which shows a similar behavior. After thermal carbonization, the product, D2, shows more apparent metalcatalyzed fibers covering the entire surface (Figure $3 \mathrm{a}$ ). This is consistent with the work by Holmes et al., ${ }^{49}$ where they suggest $\mathrm{W}$ has stronger interaction with graphene than Mo and enhances carbon nanostructure development. The similar morphology of the fibers compared to those from the Mobased guest suggests a similar reaction mechanism in this homologous system. The higher activity of the tungsten is likely to result in easier nucleation and therefore more numerous but shorter fibers, as observed. Furthermore, this higher activity is likely the reason for some fiber outgrowth on D2, since even small amounts of $\mathrm{W}$ in the $\mathrm{Cu}$-rich surface will still catalyze the growth.

As a negative control to the mechanistic hypothesis, we also used the original guest (i.e., ATM) but replaced the MOF host with a Zn-based MOF, HKUST-1(Zn) (E1). The Zn-based MOF has a similar crystal structure, ${ }^{38}$ but lacks the $\mathrm{Cu}$ centers needed for the cooperative $\mathrm{Mo}-\mathrm{Cu}$ catalytic mechanism. We prepared the host-guest $\left(\mathrm{NH}_{4}\right)_{2} \mathrm{MoS}_{4} / \mathrm{DMF} @ H K U S T-1(\mathrm{Zn})$ (F1, Figure $3 \mathrm{~b})$, which upon thermal decomposition produces $\mathrm{Zn}$ oxides $(\mathrm{ZnO})$ (Figure $\mathrm{S} 10)$. Mo-containing species from the guest bind strongly to the carbon and facilitate the scissoring of the carbon structures formed (i.e., cracking the $\mathrm{C}-\mathrm{C}$ bond of organic compounds). ${ }^{50,51}$ The micrometer rods of the carbonized product (F2) are likely the result of the collapse of the MOF structures, which in the absence of Mo retain remarkably well the original outline of the MOF crystals [carbonized sample (E2), Figure 3b, top right]. As predicted, the $\mathrm{ZnO}$ is inactive and cannot catalyze the formation of the 
$\sim 50 \mathrm{~nm}$ diameter fibers observed in the case of carbonized Moguest@Cu-MOF or W-guest@Cu-MOF.

Both new MOF-guest transformations $(\mathrm{D} 1 \rightarrow$ D2 and F1 $\rightarrow$ F2) yielded drastically different morphologies from their precursors, as in the case of our original system (B1), whereas samples prepared from the corresponding guest-free MOFs $(\mathrm{A} 1 \rightarrow \mathrm{A} 2$ and E1 $\rightarrow$ E2) primarily retained their original morphologies. This suggests that our MOF-guest treatment procedure provides a general means of creating a broad range of carbon-based structures with multiple levels of hierarchy. While shape transformations are observed in all of these MOFguest systems (B, D, and F), the resulting morphology can vary significantly depending on the catalytic and diffusion properties of the metal-based species in both guest and host.

In addition to exploring a range of carbonaceous hierarchical structures derived from MOF-guest precursors, we also demonstrated the potential usefulness of these new 3D carbon-based materials, particularly the B2, as lithium-ion battery anode $(\mathrm{LiB})$ materials (Figure 4 and Supporting
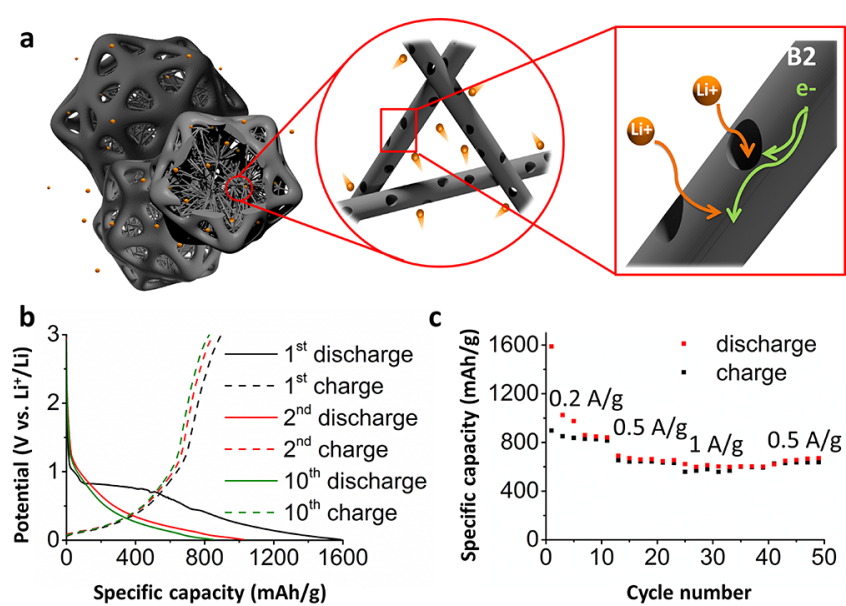

d

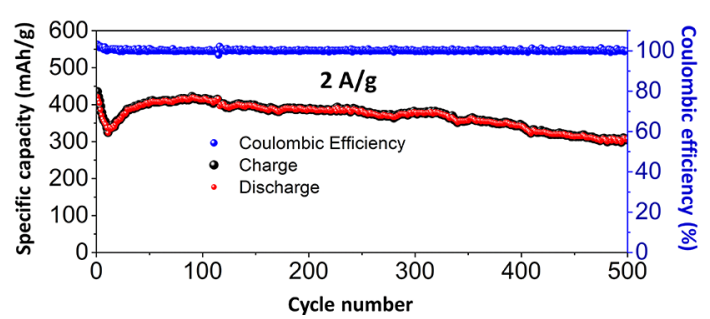

Figure 4. Hierarchically structured nano-diatom (B2) works as an anode material for Li-ion batteries. (a) Schematic drawing to illustrate good performance for fast charge/discharge due to the material's hierarchical structure; (b) charge-discharge curves at $0.2 \mathrm{~A} / \mathrm{g}$; (c) rate capability test; and (d) cyclic stability tests at $2 \mathrm{~A} / \mathrm{g}$.

Information Section 5.1). We note that the performance of our nano-diatom-based $\mathrm{LiB}$ anode is among the best achieved for carbon-based materials. ${ }^{5,33} \mathrm{We}$ obtain $830 \mathrm{mAh} / \mathrm{g}$ at $0.2 \mathrm{~A} /$ $\mathrm{g}$ (10th cycle) and over $600 \mathrm{mAh} / \mathrm{g}$ (10th cycle) at $1 \mathrm{~A} / \mathrm{g}$ (Figure $4 \mathrm{~b}, \mathrm{c}$ ). The anode also has robust cycling performance during fast charge/discharge (1 and $2 \mathrm{~A} / \mathrm{g}$, Figure S27 and Figure $4 \mathrm{~d}$ ), with less than $25 \%$ decrease (to $\sim 300 \mathrm{mAh} / \mathrm{g}$ ) after 500 cycles and consistently high Coulombic efficiency at $2 \mathrm{~A} / \mathrm{g}$. B2 shows greater cycling ability than A2, and both materials have superior performance compared with commercial graphite electrodes (Figure S27). The hierarchical structure of our nanodiatom (B2) may account for its exceptional performance as a
LiB anode material (Figure 4a). The open architecture of our nano-diatom provides free space to facilitate electrolyte infiltration, enabling fast kinetics for lithium storage. ${ }^{5}$ The mechanically strong and well-spaced fiber/web-like structures may withstand volume change during charge/discharge cycling. Furthermore, mesoporosity contributes to relatively high electrochemical utilization by increasing the ion-accessible surface area, thereby enhancing storage capacity. ${ }^{5}$ In addition, the incorporation of Mo, S (Figure 2) (<10 wt \% each obtained by TGA in Figure S18), and perhaps some $\mathrm{O}$ may also contribute to this high specific capacity, which is supported by the cathodic peak at around $0.4 \mathrm{~V}$ for the reversible electrochemical reaction of Mo-containing compounds. Note that $\mathrm{MoS}_{x}^{54,55}$ and $\mathrm{MoO}_{x}^{56}$ have cathodic peaks near $0.4-0.6 \mathrm{~V}$ $\left(\mathrm{Li}_{x} \mathrm{MOS}_{x}\right)$ and $0.4-0.5 \mathrm{~V}\left(\mathrm{Li}_{x} \mathrm{MoO}_{x}\right)$ during lithiation.

\section{CONCLUSION}

We have produced carbon-based structures with multiple levels of hierarchy via a simple, bottom-up thermochemical treatment of guest-MOF complexes of common MOF precursors. In this process, a small amount of guest (Figure S5) empowers the MOF host to undergo dramatic morphological transformations to form guest/host-dependent carbonaceous materials. Although we have explored only a small fraction of the potential $\mathrm{Cu} / \mathrm{Zn}-\mathrm{MOF}$ hosts with $\mathrm{Mo} / \mathrm{W}$-based guests for illustration, we recognize (i) the abundance of MOF-guest systems (thousands of MOFs exist ${ }^{36}$ ) that could be compatible with the process and (ii) the highly diversified carbon-based structures that can be derived from them. The current work is an initial investigation of this high-temperature guest-induced phenomenon; we still need to have a better understanding of the formation mechanisms, e.g., if the MOF's topology and molecular confinement due to the MOF's pores play a crucial role in this process. Discovery of new structures/materials that are derived from these MOF-guest systems and investigation of their formation mechanisms will be very important for future studies. Furthermore, the continued development of cheap, commercially available or easy-to-obtain, and easy-to-handle MOFs [e.g., HKUST-1 $(\mathrm{Cu})$ in this work] will enhance the potential for industrial-scale manufacturing of these hierarchical structures. We have demonstrated the applicability of one of the hierarchical carbonaceous structures as a high-performance $\mathrm{LiB}$ anode material with fast charging capability. Thus, on a more general level, the hierarchical architectures of our MOFguest-derived functional materials with the capability to incorporate various inorganic elements/compounds hold promise for a variety of future applications, such as energy storage, energy conversion, and sensing.

\section{EXPERIMENTAL SECTION}

Detailed experimental methods can be found in the Supporting Information. Briefly, HKUST-1 $(\mathrm{Cu})$ and HKUST-1(Zn) were prepared based on previously reported methods ${ }^{38,57,58}$ (detailed in Supporting Information Section 1.3.1). The above-mentioned MOFguest precursors (summarized in Table S1) were prepared by loading guest-free MOFs with guest-in-DMF ( $1 \mathrm{~g}$ of guest chemical with 100 $\mathrm{mL}$ of DMF) solution, rinsing three times with $\mathrm{DMF}$, and drying under nitrogen flow overnight (detailed in Supporting Information Section 1.3.2). The precursors were placed in an Ar atmosphere, then heated to $800{ }^{\circ} \mathrm{C}$, kept at $800{ }^{\circ} \mathrm{C}$ for $120 \mathrm{~min}$, and cooled naturally (detailed in Supporting Information Section 1.3.3). The carbonized products were then washed (detailed in Supporting Information Section 1.3.4) to remove byproducts. Methods for materials 
characterizations and $\mathrm{LiB}$ half-cell tests are given in Supporting Information Section 1.4.

\section{ASSOCIATED CONTENT}

\section{S Supporting Information}

The Supporting Information is available free of charge on the ACS Publications website at DOI: 10.1021/jacs.8b02411.

Materials and experimental details, more characterizations on $\mathbf{B} 2$ and $\mathbf{C 2}$, detailed study on the B1 $\rightarrow$ B2 morphology change at various temperatures, additional information about $\mathrm{LiB}$ tests (PDF)

\section{AUTHOR INFORMATION}

\section{Corresponding Author}

*s.smoukov@qmul.ac.uk

\section{ORCID}

Tiesheng Wang: 0000-0001-7587-7681

Hyun-Kyung Kim: 0000-0002-7897-5065

James T. Griffiths: 0000-0002-1198-1372

Yue Wu: 0000-0003-2874-8267

Kara D. Fong: 0000-0002-0711-097X

Bettina V. Lotsch: 0000-0002-3094-303X

Anthony K. Cheetham: 0000-0003-1518-4845

Stoyan K. Smoukov: 0000-0003-1738-818X

\section{Notes}

The authors declare the following competing financial interest(s): A relevant patent application is in progress by T.W., S.K.S., and H.K.K. The remaining authors declare no competing financial interests.

\section{ACKNOWLEDGMENTS}

The authors acknowledge Prof. Judith L. MacManus-Driscoll and Dr. Jingwei Hou for support. The authors would also like to show their gratitude to Phenom-World for the use of the Phenom Pro X SEM. The authors also thank Robert Cornell, Simon J. Griggs, and Sue Gymer for technical support. The project was funded through a European Research Council (ERC) grant to S.K.S. (grant number: EMATTER 280078). A.K.C. and Y.W. thank the Ras Al Khaimah Center for Advanced Materials (RAK-CAM). T.W. thanks the China Scholarship Council (CSC) for funding and EPSRC Centre for Doctoral Training in Sensor Technologies and Applications (EP/L015889/1 and 1566990) for support. W.L. acknowledges the EPSRC grants (EP/L011700/1 and EP/N004272/1). Financial support by the Max Planck Society is gratefully acknowledged. K.D.F. acknowledges support from the Winston Churchill Foundation of the United States. C.Y. thanks the Cambridge Commonwealth, European and International Trust for funding. The 3D model in Figure ${ }^{2}$, is adapted from the open-sourced 3D models (username: AA, https://www. myminifactory.com/object/dodecahedron-vacuum-3490 and username: Dizingof, https://www.thingiverse.com/ thing:1392858).

\section{REFERENCES}

(1) Georgakilas, V.; Perman, J. A.; Tucek, J.; Zboril, R. Chem. Rev. 2015, 115 (11), 4744.

(2) Li, Z.; Liu, Z.; Sun, H.; Gao, C. Chem. Rev. 2015, 115 (15), 7046.

(3) Petkovich, N. D.; Stein, A. Chem. Soc. Rev. 2013, 42 (9), 3721.

(4) Espinosa, H. D.; Filleter, T.; Naraghi, M. Adv. Mater. 2012, 24

(21), 2805.

(5) Nishihara, H.; Kyotani, T. Adv. Mater. 2012, 24 (33), 4473.
(6) Xu, Z.; Zhuang, X.; Yang, C.; Cao, J.; Yao, Z.; Tang, Y.; Jiang, J.; Wu, D.; Feng, X. Adv. Mater. 2016, 28 (10), 1981.

(7) Guan, C.; Zhao, W.; Hu, Y.; Lai, Z.; Li, X.; Sun, S.; Zhang, H.; Cheetham, A. K.; Wang, J. Nanoscale Horiz. 2017, 2, 99.

(8) Chaikittisilp, W.; Ariga, K.; Yamauchi, Y. J. Mater. Chem. A 2013, 1 (1), 14.

(9) Pachfule, P.; Shinde, D.; Majumder, M.; Xu, Q. Nat. Chem. 2016, 8 (7), 718.

(10) Kaneti, Y. V.; Tang, J.; Salunkhe, R. R.; Jiang, X.; Yu, A.; Wu, K. C.-W.; Yamauchi, Y. Adv. Mater. 2017, 29 (12), 1604898.

(11) Liu, B.; Shioyama, H.; Akita, T.; Xu, Q. J. Am. Chem. Soc. 2008, 130 (16), 5390.

(12) Xi, K.; Cao, S.; Peng, X.; Ducati, C.; Kumar, R. V.; Cheetham, A. K. Chem. Commun. (Cambridge, U. K.) 2013, 49 (22), 2192.

(13) Hu, M.; Reboul, J.; Furukawa, S.; Torad, N. L.; Ji, Q.; Srinivasu, P.; Ariga, K.; Kitagawa, S.; Yamauchi, Y. J. Am. Chem. Soc. 2012, 134 (6), 2864

(14) Shen, K.; Chen, X.; Chen, J.; Li, Y. ACS Catal. 2016, 6 (9), 5887.

(15) Kongpatpanich, K.; Horike, S.; Fujiwara, Y. I.; Ogiwara, N.; Nishihara, H.; Kitagawa, S. Chem. - Eur. J. 2015, 21 (38), 13278.

(16) Xia, B. Y.; Yan, Y.; Li, N.; Wu, H. B.; Lou, X. W.; Wang, X. Nat. Energy 2016, 1 (1), 15006.

(17) Li, H.; Yue, F.; Yang, C.; Xue, P.; Li, N.; Zhang, Y.; Wang, J. CrystEngComm 2017, 19, 64.

(18) Zou, F.; Chao, S. L.; Wang, Y. X.; Wang, Y. L.; Guan, Q. X.; Li, W. Environ. Sci.: Nano 2017, 4 (1), 46.

(19) Meng, J.; Niu, C.; Xu, L.; Li, J.; Liu, X.; Wang, X.; Wu, Y.; Xu, X.; Chen, W.; Li, Q.; Zhu, Z.; Zhao, D.; Mai, L. J. Am. Chem. Soc. 2017, 139 (24), 8212.

(20) Guan, B. Y.; Yu, X. Y.; Wu, H. B.; Lou, X. W. Adv. Mater. 2017, $1703614,1703614$.

(21) Zhang, W.; Jiang, X.; Wang, X.; Kaneti, Y. V.; Chen, Y.; Liu, J.; Jiang, J.-S.; Yamauchi, Y.; Hu, M. Angew. Chem., Int. Ed. 2017, 56 (29), 8435.

(22) Jia, G.; Zhang, W.; Fan, G.; Li, Z.; Fu, D.; Hao, W.; Yuan, C.; Zou, Z. Angew. Chem., Int. Ed. 2017, 56 (44), 13781.

(23) Su, P.; Xiao, H.; Zhao, J.; Yao, Y.; Shao, Z.; Li, C.; Yang, Q. Chem. Sci. 2013, 4 (7), 2941.

(24) Yaghi, O. M.; Li, G.; Li, H. Nature 1995, 378 (6558), 703.

(25) Allendorf, M. D.; Foster, M. E.; Léonard, F.; Stavila, V.; Feng, P. L.; Doty, F. P.; Leong, K.; Ma, E. Y.; Johnston, S. R.; Talin, A. A. J. Phys. Chem. Lett. 2015, 6 (7), 1182.

(26) Yanai, N.; Kitayama, K.; Hijikata, Y.; Sato, H.; Matsuda, R.; Kubota, Y.; Takata, M.; Mizuno, M.; Uemura, T.; Kitagawa, S. Nat. Mater. 2011, 10 (10), 787.

(27) Wang, T.; Farajollahi, M.; Henke, S.; Zhu, T.; Bajpe, S. R.; Sun, S.; Barnard, J. S.; Lee, J. S.; Madden, J. D. W.; Cheetham, A. K.; Smoukov, S. K. Mater. Horiz. 2017, 4 (1), 64.

(28) Chen, L.; Luque, R.; Li, Y. Chem. Soc. Rev. 2017, 46 (15), 4614.

(29) Wu, H. B.; Xia, B. Y.; Yu, L.; Yu, X.-Y.; Lou, X. W. Nat. Commun. 2015, 6, 6512.

(30) Xu, Y. T.; Xiao, X.; Ye, Z. M.; Zhao, S.; Shen, R.; He, C. T.; Zhang, J. P.; Li, Y.; Chen, X. M. J. Am. Chem. Soc. 2017, 139 (15), 5285.

(31) Gu, Z. G.; Zhang, D. X.; Fu, W. Q.; Fu, Z. H.; Vohra, M. I.; Zhang, L.; Wöll, C.; Zhang, J. Inorg. Chem. 2017, 56 (6), 3526.

(32) Zhu, Q. L.; Xia, W.; Zheng, L. R.; Zou, R.; Liu, Z.; Xu, Q. ACS Energy Lett. 2017, 2 (2), 504.

(33) Su, D. S.; Schlögl, R. ChemSusChem 2010, 3 (2), 136.

(34) Quan, B.; Yu, S.-H.; Chung, D. Y.; Jin, A.; Park, J. H.; Sung, Y.E.; Piao, Y. Sci. Rep. 2015, 4, 23.

(35) Stephenson, T.; Li, Z.; Olsen, B.; Mitlin, D. Energy Environ. Sci. 2014, 7 (1), 209.

(36) Moghadam, P. Z.; Li, A.; Wiggin, S. B.; Tao, A.; Maloney, A. G. P.; Wood, P. A.; Ward, S. C.; Fairen-Jimenez, D. Chem. Mater. 2017, 29 (7), 2618.

(37) Chui, S. S.-Y.; Lo, S. M.-F.; Charmant, J. P. H.; Orpen, A. G.; Williams, I. D. Science (Washington, DC, U. S.) 1999, 283, 1148. 
(38) Feldblyum, J. I.; Liu, M.; Gidley, D. W.; Matzger, A. J. J. Am. Chem. Soc. 2011, 133 (45), 18257.

(39) Müller, A.; Diemann, E.; Jostes, R.; Bögge, H. Angew. Chem., Int. Ed. Engl. 1981, 20 (11), 934.

(40) Wan, C.; Regmi, Y. N.; Leonard, B. M. Angew. Chem., Int. Ed. 2014, 53 (25), 6407.

(41) Prasad, T. P.; Diemann, E.; Müller, A. J. Inorg. Nucl. Chem. 1973, $35(6), 1895$.

(42) Wang, H. W.; Skeldon, P.; Thompson, G. E. J. Mater. Sci. 1998, 33 (12), 3079.

(43) Rahaman, M. S. A.; Ismail, A. F.; Mustafa, A. Polym. Degrad. Stab. 2007, 92 (8), 1421.

(44) Lobo, L. S. React. Kinet., Mech. Catal. 2016, 118 (2), 393.

(45) Terrones, M.; Grobert, N.; Olivares, J.; Zhang, J. P.; Terrones, H.; Kordatos, K.; Hsu, W. K.; Hare, J. P.; Townsend, P. D.; Prassides, K.; Cheetham, A. K.; Kroto, H. W.; Walton, D. R. M. Nature 1997, 388 (July), 52.

(46) Li, J.; Croiset, E.; Ricardez-Sandoval, L. Appl. Surf. Sci. 2014, 317, 923.

(47) Li, Z.; Larsson, J. A.; Larsson, P.; Ahuja, R.; M, J. M.; O Byrne, J.; Morris, M. A.; Attard, G.; Holmes, J. D. J. Phys. Chem. C 2008, 112 (32), 12201.

(48) Simoes, J. A. M.; Beauchamp, J. L. Chem. Rev. 1990, 90 (4), 629.

(49) O’Byrne, J. P.; Li, Z.; Tobin, J. M.; Larsson, J. A.; Larsson, P.; Ahuja, R.; Holmes, J. D. J. Phys. Chem. C 2010, 114 (18), 8115.

(50) Bridgewater, A. J.; Burch, R.; Mitchell, P. C. H. J. Chem. Soc., Faraday Trans. 1 1980, 76 (Iv), 1811.

(51) He, K.; Zhang, S.; Mi, J.; Chen, J.; Cheng, L. Pet. Sci. 2011, 8 (2), 134.

(52) Oberlin, A.; Endo, M.; Koyama, T. J. Cryst. Growth 1976, 32 (3), 335.

(53) De Jong, K. P.; Geus, J. W. Catal. Rev.: Sci. Eng. 2000, 42 (4), 481.

(54) Dominko, R.; Arčon, D.; Mrzel, A.; Zorko, A.; Cevc, P.; Venturini, P.; Gaberscek, M.; Remskar, M.; Mihailovic, D. Adv. Mater. 2002, 14 (21), 1531.

(55) Xiao, J.; Choi, D.; Cosimbescu, L.; Koech, P.; Liu, J.; Lemmon, J. P. Chem. Mater. 2010, 22 (16), 4522.

(56) Sun, H.; Hanlon, D.; Dinh, D. A.; Boland, J. B.; Del Rio Castillo, A. E.; Di Giovanni, C.; Ansaldo, A.; Pellegrini, V.; Coleman, J. N.; Bonaccorso, F. 2D Mater. 2018, 5 (1), 01502410.1088/2053-1583/ aa9963.

(57) Peng, Y.; Krungleviciute, V.; Eryazici, I.; Hupp, J. T.; Farha, O. K.; Yildirim, T. J. Am. Chem. Soc. 2013, 135 (32), 11887.

(58) Bhunia, M. K.; Hughes, J. T.; Fettinger, J. C.; Navrotsky, A. Langmuir 2013, 29 (25), 8140. 